\title{
Administration-Route Dependency of Absorption of Glycyrrhizin in Rats: Intraperitoneal Administration Dramatically Enhanced Bioavailability
}

\author{
Yoshikazu Yamamura, ${ }^{*}$ Tomofumi Santa, Hajime Kotaki, Katsuyoshi Uchino, \\ Yasufumi SAwADA, and Tatsuji IGA \\ The University of Tokyo Hospital, Faculty of Medicine, The University of Tokyo, 7-3-1, Hongo, Bunkyo-ku, Tokyo \\ 113, Japan. Received August 19, 1994; accepted October 26, 1994
}

\begin{abstract}
The pharmacokinetic behavior of glycyrrhizin after intravenous (i.v.), oral and intraperitoneal (i.p.) administration was compared in rats. The elimination half-life, total body clearance and volume of distribution at steady-state of glycyrrhizin were not significantly different among doses $(2,10$ and $50 \mathrm{mg} / \mathrm{kg}$ i.v. $)$. Glycyrrhizin was only detected in the plasma (maximum level: $1.3 \mu \mathrm{g} / \mathrm{ml}$ ) after oral administration of $50 \mathrm{mg} / \mathrm{kg}$. From comparison of the area under the plasma concentration-time curves after i.v. and oral administration of $50 \mathrm{mg} / \mathrm{kg}$, the bioavailability of glycyrrhizin was estimated to be approximately $1 \%$. Glycyrrhizin was stable for at least $3 \mathrm{~h}$ in gastric juice. The plasma concentration of glycyrrhizin after oral administration to neomycin-treated rats was not significantly different from that after administration to untreated rats. Furthermore, in in situ absorption study the cumulative ratio of glycyrrhizin in the mesenteric venous plasma after injection was only $1-2 \%$ of the dose. From these results, it appeared that the extremely low bioavailability by the oral route may be due to poor absorption of glycyrrhizin from the intestinal tract. On the other hand, the plasma concentration of glycyrrhizin rapidly increased after i.p. administration of doses of 2,10 and $50 \mathrm{mg} / \mathrm{kg}$, and reached a maximum level $(4.7,33.0$ and $238.9 \mu \mathrm{g} / \mathrm{ml}$, respectively) within $30 \mathrm{~min}$. The bioavailability $(65-90 \%)$ of glycyrrhizin after i.p. administration was enhanced dramatically. The i.p. route of administration may thus improve the bioavailability of glycyrrhizin.
\end{abstract}

Key words glycyrrhizin; administration-route dependency; bioavailability; peritoneal absorption

Glycyrrhizin, one of the main constituents of Glycyrrhiza glabra $\mathrm{L}$, is a glucuronide that consists of two molecules of glucuronic acid and glycyrrhetic acid and has been shown to have antiallergic activity, anti-inflammatory activity and antihepatitis activity. ${ }^{1-5)}$ This compound has been found especially useful in the treatment of patients with chronic hepatitis. ${ }^{1,2)}$ In a double-blind control trial in 133 cases of chronic active liver disease diagnosed histologically, Suzuki et al. ${ }^{6)}$ examined the therapeutic effects of i.v. administration of glycyrrhizin $(80 \mathrm{mg}$ daily for one month), and confirmed its ability to lower aminotransferase levels in chronic hepatitis. Hino et al. ${ }^{7)}$ also reported the efficacy of high dose i.v. administration of glycyrrhizin $(200 \mathrm{mg} / \mathrm{kg})$ for the treatment of chronic hepatitis.

Several studies on the pharmacokinetic behavior of glycyrrhizin after oral administration have been reported in humans and animals. ${ }^{8-11)}$ The substance was detectable in the plasma following oral administration of a large dose $(500 \mathrm{mg} / \mathrm{kg})$ to rats. ${ }^{8}$ However, the parent drug was barely detectable in human plasma after oral administration of a therapeutic dose of glycyrrhizin $(1.4-1.8 \mathrm{mg} /$ $\mathrm{kg}) .{ }^{9)}$ A possible explanation for this low bioavailability may be its hydrolysis of glycyrrhizin by gastric juice in the stomach, intestinal bacteria or other enzymatic processes in the intestinal wall. ${ }^{11)}$ However, details concerning the absorption of glycyrrhizin have not yet been fully clarified. In addition, there are few systemic studies of the administration-route dependency of this compound.

In this study, in order to elucidate the cause of the low bioavailability of glycyrrhizin after oral administration, we investigated the pharmacokinetic behavior of glycyrrhizin after oral administration to determine the cause of

* To whom correspondence should be addressed. its low bioavailability. Further, i.p. administration of glycyrrhizin was studied as an alternative administration route to the oral route to increase bioavailability.

\section{MATERIALS AND METHODS}

Chemicals Glycyrrhizin and glycyrrhetic acid obtained were of plant test grade (Nacalai Tesque Inc., Kyoto, Japan). Neomycin sulfate was obtained from Wako Pure Chemical Industries (Osaka, Japan). Capric acid as an internal standard was obtained from Tokyo Kasei (Tokyo). All other chemicals used were commercially available and of analytical grade.

Animals Male Wistar rats weighing 250-320 g (Japan Laboratory Animals Co., Tokyo) were used in this study. The animals were fed usual laboratory chow and had free access to water. They were fasted for $22 \mathrm{~h}$ before use.

In Vivo Administration Study Rats were anesthetized lightly with diethyl ether, and polyethylene cannulas were inserted into the femoral artery and vein and the urinary bladder. The animals were allowed to recover from anesthesia for at least $1.5 \mathrm{~h}$ after the surgery. After each sampling of blood, an equivalent volume of blood from another rat was transfused through the venous cannula. Plasma $(0.1 \mathrm{ml})$ was separated from the blood by centrifugation at $1680 \mathrm{~g}$ for $5 \mathrm{~min}$. Urine was pooled for $24 \mathrm{~h}$. The samples were stored at $-20^{\circ} \mathrm{C}$ until analysis.

i.v. Administration: A 2, 10 or $50 \mathrm{mg} / \mathrm{kg}$ dose of glycyrrhizin dissolved in distilled water was administered i.v. over $20 \mathrm{~s}$ (dosing volume: $1 \mathrm{ml} / \mathrm{kg}$ ). Blood samples ( $c a$. $0.3 \mathrm{ml}$ ) were collected in heparinized glass tubes through the arterial cannula at $1,3,5,15,30 \mathrm{~min}, 1,2,4$ and $6 \mathrm{~h}$ after administration of the 2 and $10 \mathrm{mg} / \mathrm{kg}$ dose, and at 
$1,3,5,15,30 \mathrm{~min}, 1,2,4,6$ and $8 \mathrm{~h}$ after administration of the $50 \mathrm{mg} / \mathrm{kg}$ dose.

Oral Administration: A single dose of glycyrrhizin (2, 10 or $50 \mathrm{mg} / \mathrm{kg}$ ) in distilled water was administered orally to rats. Blood samples $(\mathrm{ca} .0 .3 \mathrm{ml})$ were collected into heparinized glass tubes through the arterial cannula at 0.5 , $1,2,3,4,6$ and $8 \mathrm{~h}$ after administration of each dose. In another series of experiments, rats were pretreated with a $50 \mathrm{mg} / \mathrm{kg}$ oral dose of neomycin sulfate twice a day for $4 \mathrm{~d}$ in order to investigate the effect of intestinal bacteria on the absorption of glycyrrhizin. ${ }^{12)}$ Then a single dose of glycyrrhizin $(50 \mathrm{mg} / \mathrm{kg})$ was administered orally to the pretreated rats. Blood samples $(c a .0 .3 \mathrm{ml})$ were collected at the same periods following administration as above.

Intraperitoneal (i.p.) Administration: A dose of 2, 10 or $50 \mathrm{mg} / \mathrm{kg}$ of glycyrrhizin was administered intraperitoneally (dosing volume: $0.5 \mathrm{ml}$ ). Blood samples ( $c a$. $0.3 \mathrm{ml}$ ) were collected in heparinized tubes through the arterial cannula at 5, 15, 30 min, 1, 3, 5, 7 and $10 \mathrm{~h}$ after administration of the 2 and $10 \mathrm{mg} / \mathrm{kg}$ dose, and at 5,15 , $30 \mathrm{~min}, 1,3,5,8$ and $11 \mathrm{~h}$ after administration of the $50 \mathrm{mg} / \mathrm{kg}$ dose.

In Situ Intestinal Absorption Study A closed intestinal loop of ileum (length: approximately $15 \mathrm{~cm}$ ) was prepared and the mesenteric vein were cannulated according to the procedure described previously. ${ }^{13)}$

A solution of glycyrrhizin for injection was prepared by dissolving the drug in distilled water. A dose of 10 or $50 \mathrm{mg} / \mathrm{kg}$ of glycyrrhizin was injected into the loop of the ileum (dosing volume: $0.5-0.6 \mathrm{ml}$ ). After injection, mesenteric venous blood from the loop was collected at 10 -min intervals for $100 \mathrm{~min}$. Plasma was separated from the blood by centrifugation $(1680 \mathrm{~g}$, for $10 \mathrm{~min})$. Body temperature of the animals was maintained at $37-38^{\circ} \mathrm{C}$ with a heating lamp. The blood lost from the mesenteric vein was continuously replaced by intravenous infusion of heparinized blood collected from other rats (rate: $0.36 \mathrm{ml} / \mathrm{min}$ ), via the femoral vein. At the end of the experiment, the solution remaining in the loop was transferred to a 25-ml Erlenmeyer flask. The inside of the loop was washed in $20 \mathrm{ml}$ of distilled water, and the water drained was pooled in the same flask. The solution was then diluted to the mark with water and $0.1 \mathrm{ml}$ of the mixture was taken for analysis. The intestine was homogenized with 4 volumes of ice-cold distilled water and the amounts of glycyrrhizin and glycyrrhetic acid in the homogenate were assayed as described below.

Stability Study of Glycyrrhizin in Gastric Juice The stomach was isolated by midline abdominal incision in 3 rats and the pylorus was ligated under anesthesia with ether. A polyethylene cannula (No. 8, Hibiki, Tokyo) was inserted into the lower portion of the stomach, and the gastric juice was collected through the cannula for $24 \mathrm{~h}$. The $\mathrm{pH}$ in the gastric juice of 3 rats was 1.4, 1.6 and 1.6. To $1 \mathrm{ml}$ of this juice was added $0.1 \mathrm{ml}$ of water containing $5 \mu \mathrm{g}$ of glycyrrhizin, and the mixture was incubated at $37^{\circ} \mathrm{C}$ under agitation at a rate of 80 strokes/min using an incubator (Incubator Personal Ace, Taiyo Scientific Industrial Co., Tokyo). After $0.5,1,2$ or $3 \mathrm{~h}$ of incubation, $0.1 \mathrm{ml}$ of the mixture was taken and stored at $-20^{\circ} \mathrm{C}$ until analysis.
Determination of Glycyrrhizin and Its Metabolite Concentrations in Biological Fluids The concentrations of glycyrrhizin and its metabolite, glycyrrhetic acid, in plasma and urine were determined according to the HPLC method described. ${ }^{14)}$ In the homogenate of intestine and in the peritoneal fluid, each sample $(0.1 \mathrm{ml})$ was processed according to the procedure for determination of glycyrrhizin and glycyrrhetic acid concentrations in urine as above. The detection limit was $1 \mu \mathrm{g} / \mathrm{ml}$ for glycyrrhizin and $0.1 \mu \mathrm{g} / \mathrm{ml}$ for glycyrrhetic acid, respectively, in all biological samples.

Pharmacokinetic Analysis The plasma concentration profiles of glycyrrhizin after i.v. administration were fitted to Eq. 1 and those after i.p. administration to Eq. 2 using a non-linear least-squares program MULTI, ${ }^{15)}$ and the parameters $A, B, A^{\prime}, B^{\prime}, \alpha, \beta$ and $k_{a}$ were obtained. It was assumed that the drug is eliminated from the central compartment:

$$
\begin{aligned}
& C_{t}=A e^{-\alpha t}+B e^{-\beta t} \\
& C_{t}=A^{\prime} e^{-\alpha t}+B^{\prime} e^{-\beta t}-\left(A^{\prime}+B^{\prime}\right) e^{-k_{\mathrm{a}} t}
\end{aligned}
$$

where $C_{t}$ is the plasma concentration of glycyrrhizin at time $t, A$ and $B$ are ordinate intercepts, and $\alpha$ and $\beta$ are the corresponding first-order disposition rate constants. $A^{\prime}$ is $\left[F \cdot D \cdot k_{20} \cdot\left(k_{21}-\alpha\right) / V_{1} \cdot\left(k_{\mathrm{a}}-\alpha\right)(\beta-\alpha)\right.$ and $B^{\prime}$ is $\left[F \cdot D \cdot k_{\mathrm{a}} \cdot\left(k_{21}-\beta\right) / V_{1} \cdot\left(k_{\mathrm{a}}-\beta\right)(\alpha-\beta)\right] . F$ is the fraction of dose absorbed, and was assumed to be unity. The $k_{\mathrm{a}}$ is the absorption rate constant. The elimination half-life $\left(t_{1 / 2 \beta}\right)$ was calculated by dividing 0.693 by $\beta$. In the case of i.v. administration, the area under the plasma concentration-time curve $(A U C)$, the total body clearance $\left(C L_{\mathrm{tot}}\right)$ and the volume of distribution at steady state $\left(V_{\mathrm{dss}}\right)$ were calculated by $(A / \alpha+B / \beta), D \cdot \alpha \cdot \beta /\left[(A+B) \cdot k_{21}\right]$ and $\left(1+k_{12} / k_{21}\right) \cdot V_{1}$, respectively, where $D$ is dose, $V_{1}$ is the volume of distribution of the central compartment, and $k_{12}$ and $k_{21}$ are the distribution rate constant. The $A U C$ of glycyrrhizin after oral administration and i.p. administration were calculated by the trapezoidal rule and extrapolated to infinity. The bioavailability of glycyrrhizin was calculated by the ratio of $A U C$ after i.p. administration to that after i.v. administration.

Statistical Analysis Statistical analysis was performed by Student's $t$-test with $p=0.05$ as the minimal level of significance. All results were expressed as mean value \pm standard deviation.

\section{RESULTS}

Plasma Concentration Profiles after i.v. Administration The plasma concentration profiles of glycyrrhizin after i.v. administration of three different doses are shown in Fig. 1. The concentration declined biexponentially after i.v. administration of each dose. Although the metabolite, glycyrrhetic acid, was only detected in the plasma at $3 \mathrm{~min}$ after administration of the 10 and $50 \mathrm{mg} / \mathrm{kg}$ doses, the concentration was less than $0.5 \mu \mathrm{g} / \mathrm{ml}$ (data not shown). Cummulative percentages of glycyrrhizin in urine for up to $24 \mathrm{~h}$ after injection of a 2,10 and $50 \mathrm{mg} / \mathrm{kg}$ dose of the drug were only $1.3 \pm 0.4 \%, 1.9 \pm 1.2 \%$ and $3.2 \pm 0.7 \%$ of the dose, respectively, and those of glycyrrhetic acid were $0.03 \pm 0.03 \%, 0.04 \pm 0.04 \%$ and $0.01 \pm 0.02 \%$. The phar- 


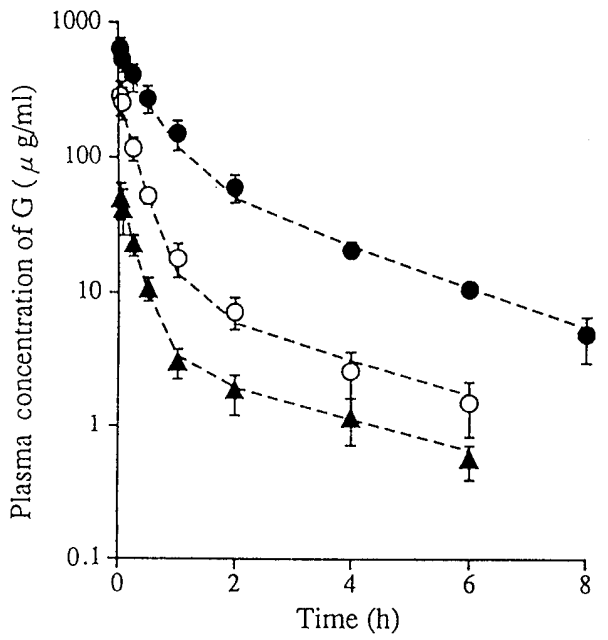

Fig. 1. Plasma Disappearance of Glycyrrhizin $(G)$ after i.v. Administration $(2(\mathbf{\Delta}), 10(\bigcirc)$ and $50(\mathbf{O}) \mathrm{mg} / \mathrm{kg}$ Dose) to Rats

The fitted curves were obtained through a nonlinear least-squares analysis of the data. Each point represents the mean of 4 determinations and vertical bars indicate the standard deviation.

TABLE I. Pharmacokinetic Parameters of Glycyrrhizin after Intravenous Administration of 2,10 and $50 \mathrm{mg} / \mathrm{kg}$ Dose to Rats

\begin{tabular}{llccc}
\hline \hline & & \multicolumn{3}{c}{ Dose $(\mathrm{mg} / \mathrm{kg})$} \\
\cline { 3 - 5 } & & 2 & 10 & 50 \\
\hline$A$ & $(\mu \mathrm{g} / \mathrm{ml})$ & $58.6 \pm 17.2$ & $271.3 \pm 182.8$ & $559.1 \pm 130.4$ \\
$\alpha$ & $\left(\mathrm{h}^{-1}\right)$ & $4.262 \pm 0.425$ & $3.793 \pm 0.684$ & $2.236 \pm 0.424$ \\
$B$ & $(\mu \mathrm{g} / \mathrm{ml})$ & $3.2 \pm 1.2$ & $10.6 \pm 5.2$ & $86.3 \pm 29.0$ \\
$\beta$ & $\left(\mathrm{h}^{-1}\right)$ & $0.262 \pm 0.017$ & $0.308 \pm 0.074$ & $0.345 \pm 0.084$ \\
$t_{1 / 2} \beta(\mathrm{h})$ & $2.7 \pm 0.2$ & $2.3 \pm 0.5$ & $2.1 \pm 0.6$ \\
$k_{12}$ & $\left(\mathrm{~h}^{-1}\right)$ & $1.626 \pm 0.307$ & $0.897 \pm 0.370$ & $0.793 \pm 0.545$ \\
$k_{21}$ & $\left(\mathrm{~h}^{-1}\right)$ & $0.470 \pm 0.090$ & $0.429 \pm 0.145$ & $0.568 \pm 0.222$ \\
$k_{10}$ & $\left(\mathrm{~h}^{-1}\right)$ & $2.431 \pm 0.421$ & $2.775 \pm 0.495$ & $1.668 \pm 0.381$ \\
$V_{\text {dss }}(\mathrm{ml} / \mathrm{kg})$ & $153.0 \pm 39.7$ & $98.6 \pm 11.7$ & $166.0 \pm 85.5$ \\
$C L_{\text {tot }}(\mathrm{ml} / \mathrm{h} \cdot \mathrm{kg})$ & $77.3 \pm 21.1$ & $80.5 \pm 14.0$ & $93.0 \pm 20.6$ \\
\hline
\end{tabular}

Pharmacokinetic parameters were calculated based on the 2-compartment model. $t_{1 / 2} \beta=0.693 / \beta \cdot V_{\mathrm{dss}}=D \cdot\left(1+k_{12} / k_{21}\right) . C L_{\mathrm{tot}}=D \cdot \alpha \cdot \beta /\left[(A+B) \cdot k_{21}\right]$. Values represent the mean \pm standard deviation of four determinations.

macokinetic parameters of glycyrrhizin are summarized in Table I. The values of $t_{1 / 2 \beta}, C L_{\mathrm{tot}}, V_{\mathrm{dss}}$ and microscopic constants for glycyrrhizin were not significantly different among doses, but the values of $k_{12}$ tended to be smaller as the dose increased.

Plasma Concentration Profiles after Oral Administration The plasma concentration profiles of glycyrrhizin after oral administration of three different doses are shown in Fig. 2. Glycyrrhizin was only detected in the plasma $1 \mathrm{~h}$ after administration of the 2 and $10 \mathrm{mg} / \mathrm{kg}$ doses, at concentrations of 0.2 and $0.4 \mu \mathrm{g} / \mathrm{ml}$, respectively. However, it was detected in all plasma samples after administration of the $50 \mathrm{mg} / \mathrm{kg}$ dose, although, its mean maximum concentration was only $1.3 \mu \mathrm{g} / \mathrm{ml}$. The $A U C$ for glycyrrhizin after administration of the $50 \mathrm{mg} / \mathrm{kg}$ dose was $7.3 \pm 1.8$ $\mu \mathrm{g} \cdot \mathrm{h} / \mathrm{ml}$. From the $A U C \mathrm{~s}$ after i.v. (Table I) and oral administration of the $50 \mathrm{mg} / \mathrm{kg}$ dose, the bioavailability of glycyrrhizin was estimated to be approximately $1 \%$. Glycyrrhetic acid was detected in the plasma $1 \mathrm{~h}$ after oral administration of the $50 \mathrm{mg} / \mathrm{kg}$ dose and its concentration was $0.4 \pm 0.2 \mu \mathrm{g} / \mathrm{ml}$; it was not detected after oral administration of the 2 and $10 \mathrm{mg} / \mathrm{kg}$ doses.

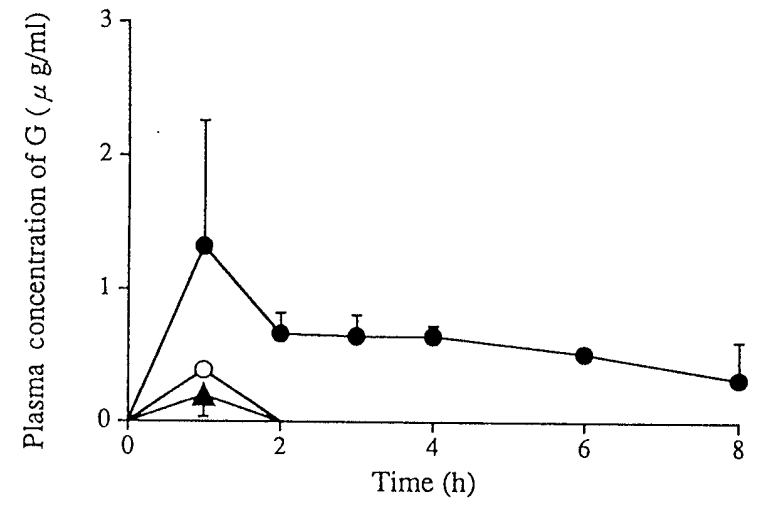

Fig. 2. Plasma Disappearance of Glycyrrhizin (G) after Oral Administration $(2(\mathbf{A}), 10(\bigcirc)$ and $50(\mathbf{O}) \mathrm{mg} / \mathrm{kg}$ Dose) to Rats

Each point represents the mean of 4 determinations and vertical bars indicate the standard deviation.

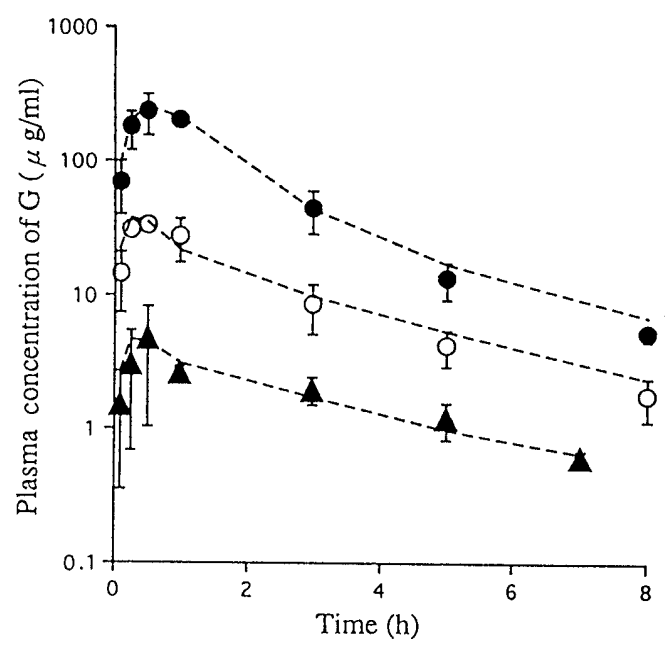

Fig. 3. Plasma Disappearance of Glycyrrhizin $(G)$ after i.p. Administration $(2(\Delta), 10(\bigcirc)$ and $50(\circlearrowleft) \mathrm{mg} / \mathrm{kg})$ to Rats

The fitted curves were obtained through a nonlinear least-squares analysis of the data. Each point represents the mean of 4 determinations and vertical bars indicate the standard deviation.

Although the plasma concentration of glycyrrhizin after each oral administration to the three rats pretreated with neomycin sulfate showed a tendency to decrease as compared with that in control rats, no significant difference was found between $A U C(7.5 \pm 2.2 v s .6 .3 \pm 2.1 \mu \mathrm{g} \cdot \mathrm{h} / \mathrm{ml})$ or plasma concentration each time in either groups.

In the experiments on stability, the percentage of glycyrrhizin remaining in gastric juice at $0.5,1,2$ and $3 \mathrm{~h}$ after incubation was $105.5 \pm 6.1 \%, 102.3 \pm 7.6 \%, 102.0 \pm$ $8.9 \%$ and $101.3 \pm 8.7 \%$, respectively.

In Situ Intestinal Absorption Study The absorption of glycyrrhizin from the intestinal tract was investigated using in situ loop technique with complete mesenteric venous blood collection. The blood-flow rate from the loop during the experiments was relatively constant $(0.29 \pm 0.03 \mathrm{ml} / \mathrm{min})$. Cumulative percentages of glycyrrhizin in the mesenteric venous plasma for up to $100 \mathrm{~min}$ after injection of a 10 and $50 \mathrm{mg} / \mathrm{kg}$ dose of glycyrrhizin were only $1.2 \pm 0.5 \%(n=4)$ and $1.9 \pm 1.3 \%(n=4)$ of the dose, and those of glycyrrhetic acid were $0.2 \pm 0.1 \%$ and $0.4 \pm 0.1 \%$, respectively. The amount of glycyrrhizin found in the homogenate of intestine was $117.9 \pm 50.3 \mu \mathrm{g}$ $(4.8 \pm 2.2 \%$ of the dose), but no glycyrrhetic acid was 
TABLE II. Pharmacokinetic Parameters of Glycyrrhizin after Intraperitoneal Administration (2, 10 and $50 \mathrm{mg} / \mathrm{kg}$ Dose) to Rats

\begin{tabular}{|c|c|c|c|}
\hline & \multicolumn{3}{|c|}{ Dose $(\mathrm{mg} / \mathrm{kg})$} \\
\hline & 2 & 10 & 50 \\
\hline$A^{\prime} \quad(\mu \mathrm{g} / \mathrm{ml})$ & $27.0 \pm 7.1$ & $274.2 \pm 98.2$ & $892.5 \pm 207.5$ \\
\hline$\alpha \quad\left(h^{-1}\right)$ & $3.636 \pm 3.908$ & $3.682 \pm 2.409$ & $1.393 \pm 0.443$ \\
\hline$B^{\prime} \quad(\mu \mathrm{g} / \mathrm{ml})$ & $3.4 \pm 0.5$ & $22.7 \pm 3.5$ & $67.6 \pm 42.0$ \\
\hline$\left(h^{-1}\right)$ & $0.236 \pm 0.018$ & $0.283 \pm 0.029$ & $0.281 \pm 0.058$ \\
\hline$t_{1 / 2} \beta(\mathrm{h})$ & $2.9 \pm 0.2$ & $2.5 \pm 0.3$ & $2.5 \pm 0.5$ \\
\hline$k_{\mathrm{a}} \quad\left(\mathrm{h}^{-1}\right)$ & $4.69 \pm 5.07$ & $4.65 \pm 2.94$ & $2.70 \pm 1.29$ \\
\hline$C L_{\text {i.p. }}(\mathrm{ml} / \mathrm{kg} \cdot \mathrm{h})$ & $137.3 \pm 14.1$ & $108.3 \pm 16.2$ & $85.6 \pm 9.1$ \\
\hline$B A(\%)$ & $63.7 \pm 15.8$ & $72.4 \pm 10.7$ & $92.7 \pm 6.8$ \\
\hline
\end{tabular}

Pharmacokinetic parameters were calculated based on the 2-compartment model $k_{\mathrm{a}}$ was determined by the residual method. $t_{1 / 2} \beta=0.693 / \beta . C L_{\mathrm{i}, \mathrm{p}}$ was the apparent clearance. $C L_{\text {i.p. }}=$ Dose $/ A U C$. Bioavailabitity $(B A)=\left(A U C_{\text {i.p. }} / A U C_{\text {i.v. }}\right) \cdot 100$. Values represent the mean \pm standard deviation of three determinations.

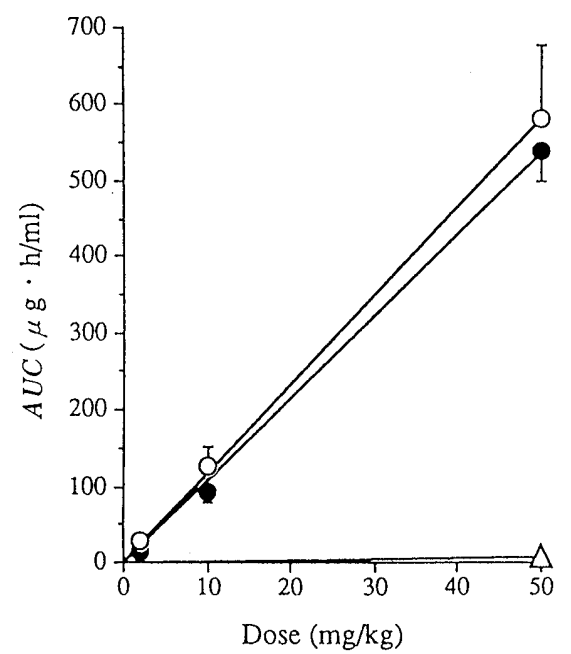

Fig. 4. Relationship between Dose of Glycyrrhizin and $A U C$ after Intravenous $(O)$, Intraperitoneal $(O)$ and Oral $(\triangle)$ Administration to Rats

Each point represents the mean of determinations and vertical bars indicate the standard deviation.

detectable. Amounts of the two substance recovered from the intestinal loop were $1926 \mu \mathrm{g}(83.8 \%$ of the dose $)$ and $5.7 \mu \mathrm{g}(0.45 \%)$, respectively.

Plasma Concentration Profiles after i.p. Administration The plasma concentration profiles of glycyrrhizin after i.p. administration of three different doses are shown in Fig. 3. It appeared rapidly in the plasma after administration of each dose and the concentration reached maximum within $30 \mathrm{~min}$. The mean maximum concentrations were $4.7,33.0$ and $238.9 \mu \mathrm{g} / \mathrm{ml}$ at the 2,10 and $50 \mathrm{mg} / \mathrm{kg}$ dose, respectively. The $t_{1 / 2}$ for glycyrrhizin was within the range of $2.5-2.9 \mathrm{~h}$. This value is almost the same as that after i.v. administration (Table II).Figure 4 shows the $A U C$ s after i.p., i.v. and oral administration plotted against dose. The $A U C$ s after i.p. administration increased linearly with dose within the range of 2 to $50 \mathrm{mg} / \mathrm{kg}$. The mean bioavailability of glycyrrhizin was estimated to be $80.0 \%$ (range $64-90 \%$, Table II).

\section{DISCUSSION}

In the present study, it was shown that the pharmaco- kinetic parameters after i.v. administration were not significantly different among doses tested. However, it is likely that the pharmacokinetics of the drug tended to be dosedependent, since the $k_{12}$ was smaller as dose increased (Table I). This may be reflected in the slower decrease of the plasma concentration in early phase at $50 \mathrm{mg} / \mathrm{kg}$ dose i.v. (Fig. 1). Ichikawa et al. ${ }^{10)}$ also reported the dosedependent pharmacokinetics of glycyrrhizin in rats, and the $A U C$ at 20 and $50 \mathrm{mg} / \mathrm{kg}$ dose increased in a greaterthan-proportional manner. The bioavailability of glycyrrhizin by the oral route of administration was extremely low, and to elucidate the reason for this, the stability of glycyrrhizin in gastric juice and the degree of intestinal absorption were investigated. We found that the substance was stable in the gastric juice of rats; this finding is consistent with our previous report on human subjects. ${ }^{16)}$ In a survey of intestinal bacteria capable of metabolizing glycyrrhizin, Hattori et al. ${ }^{17)}$ isolated Ruminococus sp. POI-3 and Clostridium-ES24-06 from human feces and found that the former strain had the ability to hydrolyze glycyrrhizin to glycyrrhetic acid at a yield of $34 \%$ after incubation for $40 \mathrm{~h}$. To investigate the effect of intestinal flora on the absorption of glycyrrhizin, rats were pretreated with neomycin sulfate, which has been reported to markedly protect against the hydrolysis of clioquinol glucuronide in the rat intestinal tract. ${ }^{12)}$ Consequently, there was no significant difference in the plasma concentration profiles of glycyrrhizin after oral administration between the neomycin-pretreated and the control rats. This finding suggests that the effect of hydrolysis by intestinal bacteria on the bioavailability of glycyrrhizin may be minimal. Furthermore, in the in situ intestinal absorption study, although glycyrrhizin was partly absorbed from intestinal tract in an unchanged form, its absorption ratio was extremely low. From these findings, the low bioavailability of glycyrrhizin after oral administration may not be due to its degradation in the gastrointestinal tract, but to its poor absorption from the intestinal tract. Sakiya et $a .^{8)}$ using the in situ recirculation perfusion technique, reported that the amount of glycyrrhizin absorbed from the intestinal tract of rats was up to approximately $20 \%$ at $120 \mathrm{~min}$. However, if $20 \%$ of the dose is absorbed, glycyrrhizin should be clearly detected after oral administration of 2,10 or $50 \mathrm{mg} / \mathrm{kg}$ dose used in the present study, because the $V_{\text {dss }}$ for this compound is extremely small (Table I) and the compound is mainly eliminated in the unchanged form ( $80-90 \%$ of i.v. dose). ${ }^{18)}$ This discrepancy between our results and those of Sakiya et $a l{ }^{8)}$ on in situ absorption experiments might be due to the difference in experimental method (e.g., an analytical procedure, the use of perfusion technique or closed loop technique).

The plasma concentration of glycyrrhizin after i.p. administration was found to be dramatically high, and its $A U C$ was comparable to that after i.v. administration. However, further study will be necessary to elucidate the transport mechanism of glycyrrhizin in the peritoneal

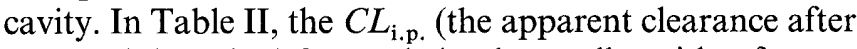
i.p. administration) for tended to be smaller with reference to the increase of bioavailability with increase of i.p. dose. This might be due to the saturation of the first-pass 
elimination of the drug in the liver.

In conclusion, there was no dose dependence in the pharmacokinetic parameters of glycyrrhizin after i.v. administration of 2 to $50 \mathrm{mg} / \mathrm{kg}$. Its low bioavailability after oral administration may be due to poor absorption from the intestinal tract. Further, the plasma concentration of glycyrrhizin after i.p. administration was dramatically high, and the $A U C$ was comparable to that after i.v. administration.

\section{REFERENCES}

1) H. Hikono, Yakugaku Zasshi, 105, 10 (1985).

2) Y. Kiso, M. Tohkin, H. Hikono, M. Hattori, T. Sakamoto, T. Namba, Planta Med., 50, 298 (1984).

3) S. Sotomatsu, Y. Takaishi, J. Hiroi, A. Namikata, N. Okano, Skin and Urol., 21, 138 (1959).

4) R. S. H. Finny, F. G. Somere, J. Pharm. Pharmacol., 10, 613 (1958).

5) K. K. Tangri, P. K. Seth, S. S. Parmar, K. P. Bhargana, Biochem. Pharmacol., 14, 1277 (1965).

6) H. Suzuki, Y. Ohta, T. Takino, K. Fujisawa, C. Hirayama, Asian Med. J., 26, 423 (1983).

7) K. Hino, H. Miyakawa, T. Kouda, K. Yasuda, K. Shimoda, M.
Iwasaki, K. Takahashi, the International Symposia of the Japanese Society of Gastroenterology (II), Japanese Society of Gastroenterology, Tokyo, 1987, pp. 295-303.

8) Y. Sakiya, Y. Akada, S. Kawano, Y. Miyauchi, Chem. Pharm. Bull., 27, 1125 (1979).

9) N. Nakano, H. Kato, H. Suzuki, H. Nakano, S. Yano, Yakuri To Rinsho, 11, 245 (1980).

10) T. Ichikawa, S. Ishida, Y. Sakiya, Y. Akada, Chem. Pharm. Bull., 34, 3734 (1979).

11) K. Terasawa, M. Bandoh, H. Tosa, J. Hirate, J. Pharmacobio-Dyn., 9, 95 (1986).

12) H. Kotaki, Y. Yamamura, Y. Tanimura, Y. Saitoh, F. Nakagawa, Z. Tamura, J. Pharmacobio-Dyn., 7, 420 (1984).

13) H. Kotaki, Y. Yamamura, Y. Tanimura, Y. Saitoh, F. Nakagawa, Z. Tamura, J. Pharmacobio-Dyn., 6, 881 (1983).

14) Y. Yamamura, J. Kawakami, T. Santa, H. Kotaki, K. Uchino, Y. Sawada, T. Iga, J. Chromatogr., 567, 151 (1991).

15) K. Yamaoka, T. Tanigawara, T.Nakagawa, T. Uno, J. Pharmacobio-Dyn., 4, 879 (1981).

16) Y. Yamamura, J. Kawakami, T. Santa, H. Kotaki, K. Uchino, Y. Sawada, N. Tanaka, T. Iga, J. Pharm. Sci., 81, 1042 (1992).

17) M. Hattori, T. Sakamoto, T. Yamagishi, K. Sakamoto, K. Konishi, K. Kobashi, Y. Namba, Chem. Pharm. Bull., 33, 210 (1985).

18) S. Ishida, Y. Sakiya, T. Ichikawa, Z. Taira, Chem. Pharm. Bull., 40, 1917 (1992). 